\title{
Hispania Nostra premia a través de tres categorías las buenas prácticas en la conservación del patrimonio cultural y natural
}

\begin{abstract}
Desde 2011 la asociación Hispania Nostra junto con la Fundación Banco Santander convocan los premios a las buenas prácticas en conservación del patrimonio cultural y natural con el objetivo de destacar proyectos y actuaciones ejemplares de salvaguarda. Las candidaturas cada vez más numerosas consolidan unos galardones que se extienden más allá de la puesta en valor patrimonial, premiando la importancia que estas acciones tienen en relación con el desarrollo sostenible, el crecimiento económico, la mejora de la calidad de vida y del medioambiente. Presentamos las actuaciones ganadoras en 2021.
\end{abstract}

Antonio Zárate Martín | Instituto Universitario de Ciencias Ambientales, Universidad Complutense de Madrid

URL de la contribución <http://www.iaph.es/revistaph/index.php/revistaph/article/view/5004>

Los premios Hispania Nostra reconocen el creciente interés de la sociedad por la conservación y puesta en valor de los valores patrimoniales, y la importancia de las acciones acometidas en ese contexto para el desarrollo sostenible, el crecimiento económico, la mejora de la calidad de vida y del medioambiente. Con esos objetivos, los premios se agrupan en tres categorías: una dedicada a la intervención en el territorio o en el paisaje; otra a la conservación del patrimonio como factor de desarrollo económico y social; y una tercera que atiende a la señalización y difusión del patrimonio cultural y natural. Todas las candidaturas presentadas son de gran calidad e interés técnico y profesional, y muestran apoyos sociales, entusiasmo e ilusiones colectivas, siempre con las perspectivas de la inclusión social y el equilibrio ambiental.

Las candidaturas premiadas en 2021 han sido: las actuaciones de rehabilitación en el entorno del Camino de Santiago francés a su paso por el entorno del embalse de Yesa, en Ruesca (Zaragoza), en la primera categoría; la rehabilitación y reconstrucción de edificio hospitalario y anexos de la Isla del Rey en el Puerto de Mahón para centro cultural, y el proyecto de gestión del patrimonio Real Maestranza de Caballería de Ronda (RMR), en la segunda; y Andando Córdoba, en la tercera. Se trata de actuaciones desarrolladas en ámbitos espaciales diferentes y de naturaleza distinta, pero cada una de ellas supone una aportación concreta a la conservación y difusión de los valores patrimoniales de la cul- tura europea, un instrumento de crecimiento económico para los entornos locales y un soporte para la resiliencia medioambiental.

El premio a las actuaciones de rehabilitación en el marco del Camino de Santiago francés a su paso por el entorno del embalse de Yesa, presentado por la Confederación Hidrográfica del Ebro y el Gobierno de Aragón, reconoce su contribución al desarrollo a partir de las relaciones entre patrimonio, paisaje y territorio. El proyecto se centra en la localidad de Ruesta, al norte de la provincia de Zaragoza, atravesada por el Camino de Santiago francés y en abandono tras la construcción del embalse de Yesa en 1960, situación que provocó la desaparición de los cultivos del valle y la expulsión de la población. Las labores de rehabilitación realizadas garantizan la recuperación del conjunto y contribuyen a mejorar el Camino de Santiago francés en este entorno. A través del fomento del turismo mediante la propuesta de un camping y de las actividades de conservación, mantenimiento y recuperación, destacando la restauración de la calle del centro de Ruesta y de las ermitas de San Jacobo (Santiago) de Ruesta, de San Juan de Ruesta y de San Juan de Sigüés (BIC asociados al Camino de Santiago), se consigue fijar población en los municipios próximos.

Galardonada en la segunda categoría, la rehabilitación y reconstrucción del edificio hospitalario y anexos de la Isla del Rey en el Puerto de Mahón (Menorca) para cen- 


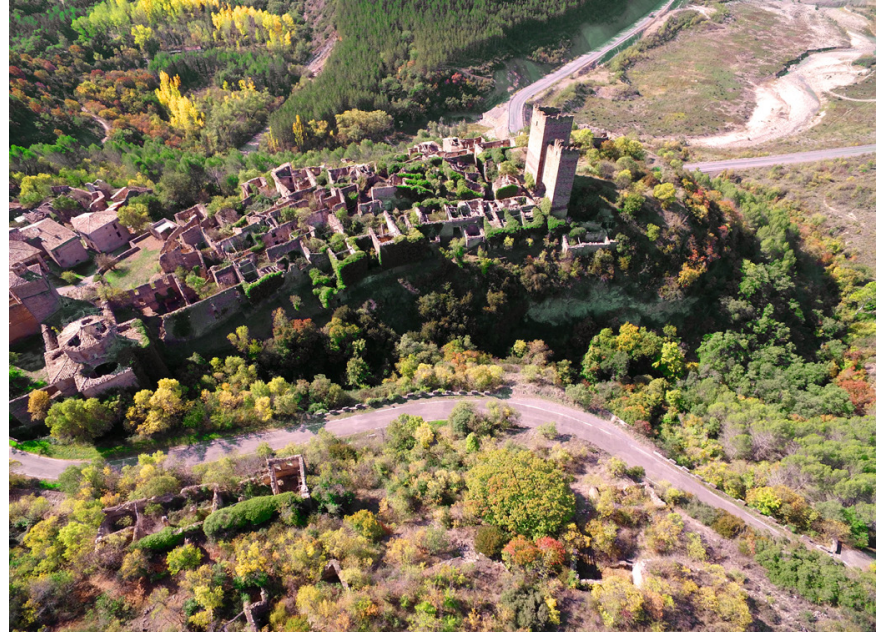

Vista de Ruesta (Zaragoza) desde dron | foto Sebastián Arquitectos

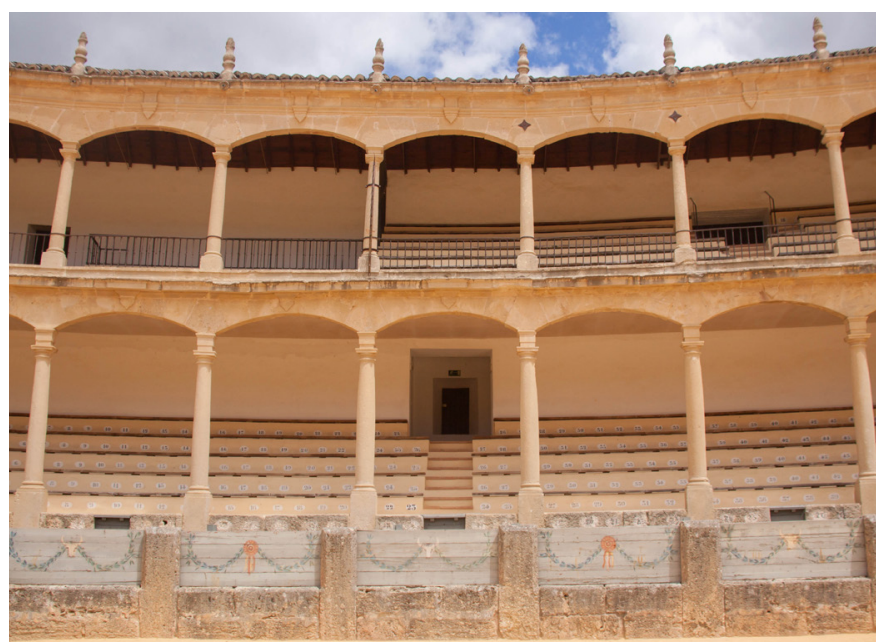

Plaza de Toros de Ronda (Málaga) | foto ChrisGoldNY

tro cultural recupera un elemento relevante de valor patrimonial y paisajístico, aparte de su significado histórico. Se trata del que fuera hospital naval británico construido en 1711 en un lugar emblemático, donde desembarcó Alfonso III en 1287 para conquistar la isla a los musulmanes. Tras pasar, también, por manos francesas, en el año 1802 revirtió definitivamente a la Corona española y siguió funcionando para el ejército español hasta 1956, siendo posteriormente abandonado el edificio y sumido en el inevitable deterioro. Lo que se ha premiado es la labor de rehabilitación iniciada en 2004 por un grupo de ciudadanos, constituidos en 2005 como Fundación Hospital de la Isla del Rey con apoyo del Ayuntamiento.

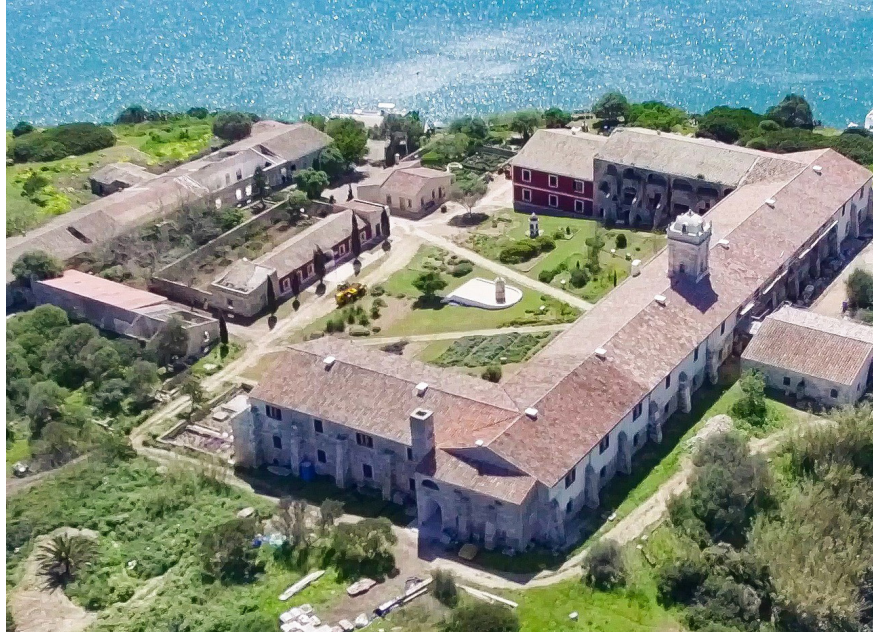

Vista aérea del Hospital en la Isla del Rey de Mahón | foto FHIR

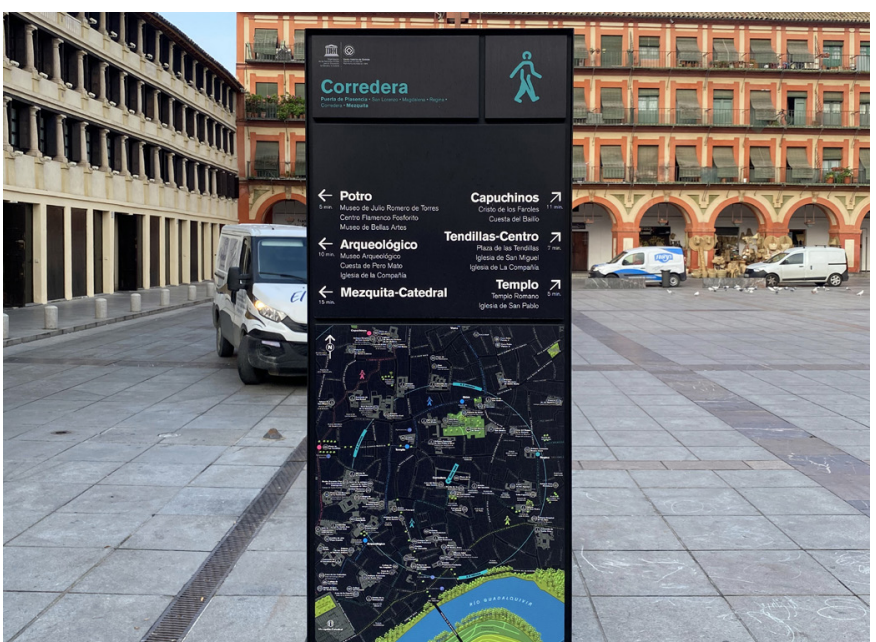

Andando Córdoba. Ejemplo de señalética en la calle | foto Luis Muñoz

Hoy el espacio funciona como centro cultural y de arte contemporáneo, centro de interpretación del Puerto de Mahón y como museo de Medicina, Cirugía y Farmacia del siglo XVIII, con una biblioteca. Se ha acondicionado también un jardín de plantas usadas en el hospital por sus propiedades medicinales que, junto con los restantes elementos del conjunto, actúa como atracción turística y, por lo tanto, de generación de riqueza.

Dentro de esa misma categoría y ex aequo fue premiado el Proyecto de gestión del patrimonio Real Maestranza de Caballería de Ronda-RMR. Se reconoce así la labor de una institución cultural fundada en 1573, indispensa- 


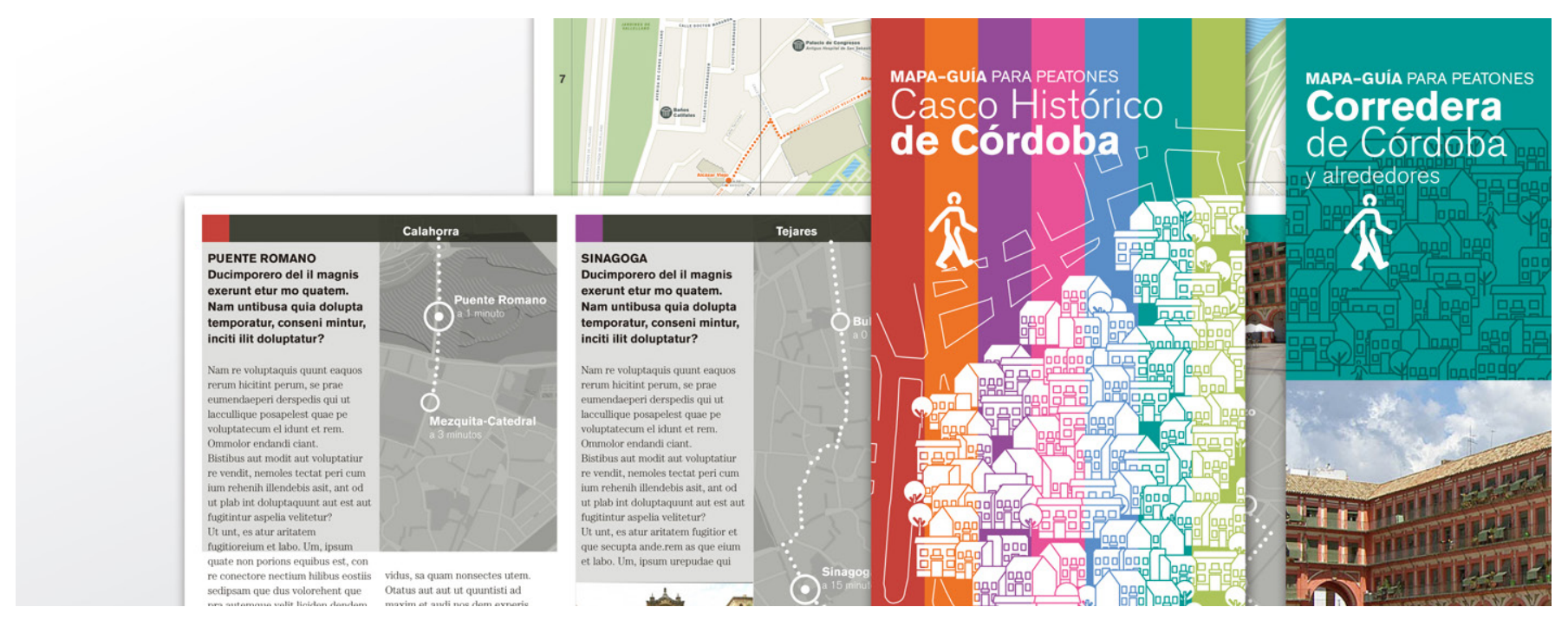

Premio a la señalización y difusión del patrimonio cultural y natural. Andando Córdoba

ble para la historia de Ronda y su entorno, y se premian tareas iniciadas en 1997 para la recuperación de edificios $\mathrm{y}$ fondos documentales de un legado secular de elevado valor patrimonial. Los trabajos comenzaron en 1996 con la reforma de la plaza de toros, y siguieron con el museo de la Tauromaquia, la nueva biblioteca, la Sala de investigación, la colección de armas antiguas, de guarniciones de Orleans, el Salón de grado, el Picadero, el Patio de caballos y la Sala de Real Maestranza. A lo largo de diez años se han recibido nueve millones de visitantes y más de cien mil espectadores y asistentes a actividades desarrolladas en la plaza y resto de instalaciones. Este movimiento genera trabajo y empleo, ha estimulado la restauración de numerosos edificios y monumentos de Ronda y la Serranía, y ha permitido multiplicar las instalaciones hoteleras y las pernoctaciones en la zona.

En Andando Córdoba, sistema de orientación y señalización para caminantes en el casco histórico de Córdoba, premiado en la tercera categoría, se reconoce el interés de un proyecto integral y multisoporte de señalización, orientación, información e interpretación del casco histórico cordobés, para facilitar su comprensión y la experiencia de la visita. A partir de un análisis estratégico se proponen siete itinerarios para residentes y foráneos, con hitos de valor patrimonial en cada uno de ellos, que parten de las puertas de la muralla y terminan en la Mezquita-Catedral. Así se pretende también distri- buir el flujo turístico por todo el casco histórico, descongestionando el entorno de la Mezquita-Catedral, lo que puede servir de modelo para otras ciudades españoles con exceso de presión turística en espacios muy concretos y reducidos, como es el caso de las ciudades patrimonio mundial. Un sistema de señalización, orientación e interpretación distribuido a lo largo de estas rutas facilita la movilidad, junto con un plano-guía y otro temático, así como una página web que recoge itinerarios, mapas, zonas y puntos de interés.

En conclusión, todas las actuaciones premiadas en 2021, como las de años anteriores, vienen a convertirse en elementos de referencia y estímulo para una sociedad que aprecia su pasado y desea transmitirlo a las generaciones futuras como parte de sus señas de identidad colectiva. Las candidaturas son cada vez más numerosas, como prueba de ese interés de la sociedad por la salvaguarda de sus valores patrimoniales, y los premios concedidos por Hispania Nostra se consolidan, de este modo, como máximo galardón de prestigio, cumpliendo una importante función de apoyo a la conservación de nuestro patrimonio cultural y al desarrollo económico y social de los lugares desde criterios de sostenibilidad, resiliencia y equilibrio medioambiental. 